\title{
Burden, Predictors and Short-Term Outcomes of Traumatic Brain Injury Among Patients Admitted to Ugandan Intensive Care Units
}

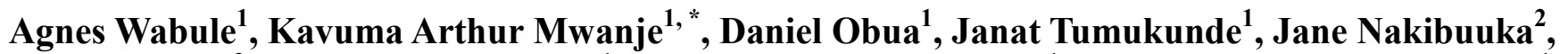 \\ Samuel Kizito $^{3}$, Peter Kaahwa Agaba ${ }^{1}$, Mary Theresa Nabukenya ${ }^{1}$, Emmanuel Timarwa Ayebale $^{1}$, \\ Arthur Kwizera ${ }^{1}$
}

${ }^{1}$ Department of Anaesthesia \& Critical Care, College of Health Sciences, Makerere University, Kampala, Uganda

${ }^{2}$ Directorate of Medical Services, Mulago National Referral Hospital, Kampala, Uganda

${ }^{3}$ Department of Clinical Epidemiology \& Biostatistics, College of Health Sciences, Makerere University, Kampala, Uganda

Email address:

kart227@yahoo.com (K. A. Mwanje)

${ }^{*}$ Corresponding author

\section{To cite this article:}

Agnes Wabule, Kavuma Arthur Mwanje, Daniel Obua, Janat Tumukunde, Jane Nakibuuka, Samuel Kizito, Peter Kaahwa Agaba, Mary Theresa Nabukenya, Emmanuel Timarwa Ayebale, Arthur Kwizera. Burden, Predictors and Short-Term Outcomes of Traumatic Brain Injury Among Patients Admitted to Ugandan Intensive Care Units. American Journal of Clinical and Experimental Medicine.

Vol. 8, No. 4, 2020, pp. 71-77. doi: 10.11648/j.ajcem.20200804.13

Received: June 15, 2020; Accepted: August 3, 2020; Published: August 13, 2020

\begin{abstract}
Severe Traumatic brain injury (STBI) is a leading cause of morbidity and mortality among young individuals worldwide with worse outcomes being registered in low-income countries. Brain trauma foundation recommends the management of patients with TBI in the intensive care unit (ICU) to prevent secondary brain injury for improved outcome. However, Uganda being a low-income country, still grapples with the availability of ICU resources and space. Information regarding burden, predictors and short-term outcomes of ICU patients with TBI in Uganda has never been reconnoitered. A multicenter prospective observational cohort was conducted between 2013 to 2015 at four Ugandan ICUs. During the study period, we consecutively enrolled 387 critically ill, adult patients with TBI to determine the burden, predictors and short term outcomes in these patients. Baseline demographics, clinical and treatment parameters were recorded and followed till discharge from ICU or death. Of 387 patients enrolled in the study, 277 (71.6\%) had moderate TBI, while $113(29.2 \%)$ patients had STBI. The highest burden of TBI was recorded among patients assaulted through mob violence, recorded at $17 / 21$ (81.0\%), as shown in table 5. The overall mortality was at 34.4\% (95/277) among patients with moderate or severe TBI, and $46.9 \%$ (53/113) among patients with STBI alone. Mortality was relatively higher among patients brought by the police, and those brought in at night. Multivariate analysis showed patient intubation, lack of antibiotic use, failure to transfuse, tracheostomy tube not inserted, and being involved in RTA or sustaining a fall were significantly associated with mortality among patients with TBI. We found a high burden of TBI and mortality among ICU patients. Despite limited resources in the local setting, inexpensive and locally available measures can reduce on the length of patient's stay in the ICU and eventually decrease on the mortality. Improvement in prehospital as well as early trauma and airway care, antibiotic use, blood transfusion plus public health safety measures may reduce on the burden of TBI as well as improve outcomes.
\end{abstract}

Keywords: TBI, Burden, Predictors, Critically Ill, ICU

\section{Introduction}

Traumatic brain injury (TBI) is a global public health concern infringing on socio-economic development. In high- income countries like the United States of America and the United Kingdom, there are approximately 275,000 
admissions per year in each country [1]. Such numbers are higher in low-income countries such as Uganda, South Africa, Nigeria, and Kenya [2, 3].

While the causes of TBI have fluctuated over the years with falls among young children and elderly surpassing road traffic accidents (RTAs) in the high-income countries [4], RTAs remain among the leading cause of TBI and death worldwide, with males being predominantly affected [5]. RTAs involving pedestrians and motorcycle riders are still the leading cause of TBI in low-income countries such as Uganda [6].

Despite the advancement in treatment options, TBI still causes significant mortality around the world [4, 7-11] and the World Health Organization (WHO) estimates that injuryrelated incidents will be the fifth most prevalent cause of death worldwide by the year 2030 [5]. Mortality in some high income-countries ranges from 10.8 to $44.2 \%$, while in Uganda and Kenya, it ranges between $25.8 \%$ and $54 \%$ [3, 12, 13$]$.

Just like most low-income countries, there is a paucity of high-quality epidemiological data on the burden, predictors, and outcomes of TBI in Uganda. The burden of RTAs has significantly risen in Uganda in the last decade, which parallels the surge in the number of commuter motorbikes in the city and increased population growth [8, 14]. Unfortunately, the health system in the country is not sufficiently equipped to manage significant numbers of patients with severe traumatic brain injury (STBI). It is recommended that such patients be treated in Intensive Care Units (ICUs) since protocolized care in the ICU has been shown to improve outcome in patients with STBI [15-17]. Ugandan ICUs are resource-constrained with few functional beds, low human resource and high mortality rates [18-20]. It is also unknown how patients with TBI admitted to Ugandan ICUs compare with others in either a similar or higher income setting.

We sought to determine the burden, predictors, and shortterm outcomes among patients with TBI admitted to Ugandan ICUs.

\section{Methods}

\subsection{Study Background}

We conducted a prospective observational multicenter cohort study among adult patients between January 2013 to June 2015 at Mulago National Referral ICU, Uganda Heart Institute ICU, International Hospital Kampala ICU and Nakasero Hospital Limited ICU in Kampala city, Uganda.

\subsection{Sample Size and Eligibility Criteria}

We calculated the sample size for the prevalence of TBI post hoc using Kish Leslie method of 1965 , where $n=Z^{2} \mathrm{pq} / \mathrm{d}^{2}$ with $Z=1.96$, where $p$ is the hypothesized population with TBI. This was estimated from a study by Mehmood A et al. which, was $62.9 \%$ [30]. Finally, $\mathrm{d}$ is a measure of the study's power, the probability of committing a type 2 error, and this was set at 0.05 . The calculated sample size was 359 participants.

All patients requiring mechanical ventilation were recruited into the study with informed consent from the next of kin. Eligible patients who were less than 18 years, brain dead and those whose next of kin refused to give consent to participate in the study were excluded.

\subsection{Patient Assessment}

At study enrolment, we collected socio-demographic data, medical history, social history (smoking, alcohol use, education level), comorbidities and clinical scores. Clinical characteristics included organ function status, surgical status, comorbidities, biochemical and hematological values. Treatment characteristics included sedation drugs, use of restraints, mode of airway control, mode of ventilation, chest $\mathrm{X}$-ray findings, and route of administration of feeds. Severe TBI and Moderate TBI were defined as having an admission GCS of equal to or less than 8 and above 8 respectively. Patients' characteristics, investigations and Organ support parameters were all recorded in study record forms. The primary outcome was death while Secondary outcome was the length of ICU stay.

\subsection{Ethical Approval}

Both Research and Ethics Committee of Makerere University and Uganda National Council for Science and Technology approved this study. All study participants were treated for TBI as directed by the attending anesthesiologist or Intensivists.

\subsection{Data Management and Statistical Analysis}

All data were entered in a data entry sheet in excel and analyzed using STATA (StataCorp. 2014. Stata Statistical Software: Release 14.1. College Station, TX: StataCorp LP).

We determined the burden of TBI and STBI with the numerator being the number of patients with TBI and STBI respectively and denominator the total number of patients enrolled in the study. We reported the overall prevalence of TBI as well as prevalence among special groups and their corresponding $95 \%$ confidence intervals. To compute mortality among TBI patients, the total number of participants who died was divided by the total number of participants with TBI. Data were summarized using proportions/percentages for categorical variables and means with standard deviations for continuous data. To compare characteristics between categorical variables; Chi-square and Fisher's exact test were used. Significance was set at a pvalue of less than 0.05 .

To assess the predictors of mortality among patients with TBI, we used logistic regression. Bivariate analysis was done for each independent predictor and if it had a P-values of 0.2 or less it was entered into a multivariate logistic model. We assessed for interaction then confounding at $10 \%$ difference between adjusted and unadjusted models. Significance was set at a p-value of 0.05 and less. 


\section{Results}

During the study period, we recruited 387 patients admitted in four ICUs majority of whom, 211 (54.5\%) were below 35 years of age and were predominantly males 327 $(84.5 \%)$ (Table 1$)$.

Table 1. Demographic and pre-admission information among patients admitted to Ugandan ICUs.

\begin{tabular}{lll}
\hline Variable & n (387) & Percentage \\
\hline Age & & \\
Less than 35 & 211 & 54.52 \\
At least 35 & 61 & 15.76 \\
Unknown & 115 & 29.72 \\
Sex of the patient & & \\
Male & 327 & 84.5 \\
Female & 60 & 15.5 \\
Referral & & \\
The patient was referred into the hospital & 80 & 20.67 \\
The patient was not referred & 307 & 79.33 \\
Time when the patient was brought to the hospital & & \\
Day & 200 & 51.68 \\
Evening & 77 & 19.9 \\
Night & 110 & 28.42 \\
Patient was brought by: & & \\
Family or relatives & 126 & 32.6 \\
Police & 99 & 25.6 \\
Not known & 162 & 41.9 \\
\hline
\end{tabular}

Road traffic accidents accounted for almost half of the mechanisms of injuries, at 188 (48.6\%), as shown in table 2 Brain CT scan was the commonest investigation done, in 149 patients (38.7\%), while $237(61.2 \%)$ received antibiotics (table 3). All patients were mechanically ventilated through endotracheal or tracheostomy tubes with various modes. Mean age of patients was 32 years with males constituting $76 \%$ of study subjects. All patients were fed enterally, and $56 \%$ had had some form of surgical intervention during their ICU admission.

Table 2. Mechanism, pattern, and severity of injuries among patients admitted to Ugandan ICUs.

\begin{tabular}{lll}
\hline Variable & N (387) & Percentage \\
\hline Mechanism & 188 & 48.58 \\
RTA & 17 & 4.39 \\
Thermal burns & 11 & 2.84 \\
Falls & 21 & 5.43 \\
Mob violence & 34 & 8.79 \\
Assault & 116 & 29.9 \\
Others & & \\
Number of injuries & 357 & 92.5 \\
Not multiply injured & 29 & 7.5 \\
Multiply injured & & \\
Glasgow Coma Scale & 111 & 28.7 \\
Above 12 & 163 & 42.1 \\
Between 8 and 12 & 113 & 29.2 \\
Below 8 & & \\
Blood pressure measurements & 164 & 42.38 \\
Normotensive & 85 & 21.96 \\
Hypertensive & 82 & 21.19 \\
Hypotensive & 56 & 14.47 \\
Unrecorded & & 37.21 \\
Pulse rate & 144 & \\
Normal & & \\
\hline
\end{tabular}

\begin{tabular}{lll}
\hline Variable & N (387) & Percentage \\
\hline High & 104 & 26.87 \\
Low & 29 & 7.49 \\
Unrecorded & 110 & 28.42 \\
\hline
\end{tabular}

Table 3. Investigations and interventions.

\begin{tabular}{lll}
\hline Variable & N & Percentage \\
\hline Investigations done & & \\
X-ray & 80 & 20.73 \\
Ct scan & 149 & 38.7 \\
Ultrasound & 51 & 13.18 \\
Other investigations & 54 & 13.95 \\
Interventions & & \\
Cardio Pulmonary Resuscitation & 40 & 10.34 \\
Intubation & 123 & 31.78 \\
Chest drain & 12 & 3.1 \\
Airway management & 180 & 46.51 \\
Others** & 118 & 30.65 \\
Treatment & & \\
Antibiotics & 237 & 61.24 \\
Analgesia & 227 & 58.66 \\
Anesthesia & 56 & 14.47 \\
Anticonvulsants & 106 & 27.39 \\
Transfusion & 43 & 11.11 \\
Tracheostomy tube & 76 & 19.64 \\
Diuretics & 81 & 20.93 \\
Others & 52 & 13.44 \\
\hline
\end{tabular}

Data shows that $48.8 \%$ of TBI patients had undergone some form of surgery compared to those who didn't have TBI (33.8\%). Comorbidities, seizures and cardiac arrests were more prevalent among patients without STBI (table 4).

Table 4. Comparing characteristics between patients with STBI and those without STBI.

\begin{tabular}{llll}
\hline \multirow{2}{*}{ Characteristics } & No STBI (274) & STBI (113) & \multirow{2}{*}{ P value } \\
\cline { 2 - 3 } Comorbidities & N (percentage) & N (percentage) & \\
HIV & $61(22.08)$ & $24(20.73)$ & 0.001 \\
Diabetes mellitus & $29(10.39)$ & $3(2.44)$ & 0.003 \\
Hypertension & $18(6.49)$ & $4(3.66)$ & 0.002 \\
Acute kidney injury & $7(2.60)$ & $6(4.88)$ & 0.874 \\
Acute respiratory & $46(16.88)$ & $21(18.29)$ & 0.042 \\
distress syndrome & $36(12.99)$ & $32(28.05)$ & 0.894 \\
Sepsis & & & \\
PH & $68(24.68)$ & $23(20.73)$ & 0.49 \\
Normal & $142(51.95)$ & $70(62.20)$ & \\
Acidosis & $25(9.09)$ & $7(6.10)$ & \\
Alkalosis & & & \\
Hemoglobin & $75(27.27)$ & $26(23.17)$ & 0.551 \\
Normal & $199(72.72)$ & $87(76.83)$ & \\
Anemia & $93(33.77)$ & $55(48.78)$ & 0.055 \\
Surgery done & $39(14.29)$ & $18(15.85)$ & 0.758 \\
Seizure & $57(20.78)$ & $10(8.54)$ & 0.028 \\
Cardiac arrest & $28(10.39)$ & $26(23.17)$ & 0.016 \\
Self-extubation & & & \\
\hline
\end{tabular}

Overall, 277 (71.6\%) patients had TBI, of whom $113(29.2 \%)$ had severe TBI. The highest burden of TBI was recorded among patients assaulted through mob violence, recorded at $81.0 \%$ (17/21) (Table 5). The overall mortality was at $34.4 \%(95 / 276)$ among patients with TBI, and 46.9\% (53/113) among patients with STBI. Mortality was relatively higher among patients brought by the police, and those brought in the night (table 6). 
Table 5. Prevalence of traumatic brain injury among patients admitted to Ugandan ICUs.

\begin{tabular}{llll}
\hline Category & $\mathbf{n} / \mathbf{N}$ & Prevalence $\mathbf{( 9 5 \%} \mathbf{C I})$ & P-value \\
\hline $\begin{array}{l}\text { Overall prevalence of TBI } \\
\text { Severe TBI }\end{array}$ & $277 / 387$ & $71.6(66.9-75.9)$ & \\
Sex & $113 / 387$ & $29.2(24.9-33.9)$ & \\
Male & & & \\
Female & $242 / 327$ & $74.0(69.0-78.5)$ & \\
Age & $35 / 60$ & $58.3(45.2-70.4)$ & 0.04 \\
Less than 35 & $155 / 211$ & $73.5(67.0-79.0)$ & \\
At least 35 & $40 / 61$ & $65.6(52.5-76.6)$ & \\
Number of injuries & & & \\
Not multiply injured & $273 / 357$ & $76.5(71.7-80.6)$ & \\
Multiply injured & $4 / 29$ & $13.8(4.9-33.0)$ & \\
Mechanism of injury & & & \\
No mob violence & $260 / 366$ & $71.0(66.2-75.5)$ & \\
Mob violence & $17 / 21$ & $81.0(56.4-93.3)$ & \\
\hline
\end{tabular}

At multivariate analysis, intubation, failure to transfuse, or administer antibiotics (table 6), tracheostomy tube not inserted and being involved in RTA (table 7) or sustaining a fall were significantly associated with mortality among patients with TBI.

Table 6. Mortality among patients with TBI admitted to Ugandan ICUs.

\begin{tabular}{|c|c|c|c|}
\hline Category & $n / N$ & Mortality (95\% CI) & P-value \\
\hline Overall mortality among TBI patients & $95 / 276$ & $34.4(29.0-40.3)$ & \\
\hline Mortality among patients with STBI & $53 / 113$ & $46.9(37.8-56.2)$ & \\
\hline \multicolumn{4}{|l|}{ Sex } \\
\hline Male & $82 / 241$ & $34.0(28.3-40.3)$ & 0.717 \\
\hline Female & $13 / 35$ & $37.1(22.3-54.9)$ & \\
\hline \multicolumn{4}{|l|}{ Age } \\
\hline Less than 35 & $50 / 155$ & $32.3(25.3-40.1)$ & 0.651 \\
\hline At least 35 & $14 / 40$ & $35.0(21.4-51.5)$ & \\
\hline \multicolumn{4}{|l|}{ Patient was brought by: } \\
\hline Family or relatives & $31 / 93$ & $33.3(24.4-43.7)$ & 0.05 \\
\hline Police & $33 / 73$ & $45.2(34.0-56.9)$ & \\
\hline Not known & $31 / 110$ & $28.2(20.5-37.4)$ & \\
\hline \multicolumn{4}{|l|}{ Referral } \\
\hline Patient was referred into the hospital & $21 / 61$ & $34.4(23.4-47.5)$ & 0.999 \\
\hline Patient was not referred & $74 / 215$ & $34.4(28.3-41.1)$ & \\
\hline \multicolumn{4}{|l|}{ Time when the patient was brought } \\
\hline Day & $39 / 128$ & $30.5(23.0-39.1)$ & 0.148 \\
\hline Evening & $20 / 64$ & $31.3(20.9-43.9)$ & \\
\hline Night & $36 / 84$ & $42.9(32.5-53.8)$ & \\
\hline \multicolumn{4}{|l|}{ Intubation } \\
\hline Patient was intubated & $57 / 101$ & $56.4(46.5-65.9)$ & 0.001 \\
\hline Patient was not intubated & $38 / 175$ & $21.7(16.2-28.5)$ & \\
\hline \multicolumn{4}{|l|}{ Antibiotic use } \\
\hline No antibiotic given & $52 / 173$ & $30.1(23.6-37.4)$ & 0.048 \\
\hline Antibiotics were given & $43 / 103$ & $41.7(32.5-51.6)$ & \\
\hline
\end{tabular}

Table 7. Factors associated with mortality among patients with TBI admitted to Ugandan ICUs.

\begin{tabular}{|c|c|c|c|c|}
\hline \multirow{2}{*}{ Characteristics } & \multicolumn{2}{|l|}{ Bivariate analysis } & \multicolumn{2}{|c|}{ Multivariate analysis } \\
\hline & OR $(95 \% \mathrm{CI})$ & P-Value & OR $(95 \% \mathrm{CI})$ & P-Value \\
\hline \multicolumn{5}{|l|}{ Sex } \\
\hline Male & 1 & & 1 & \\
\hline Female & $1.15(0.55-2.39)$ & 0.717 & $0.92(0.69-1.24)$ & 0.602 \\
\hline \multicolumn{5}{|l|}{ Age } \\
\hline Less than 35 & 1 & & & \\
\hline At least 35 & $1.14(0.86-1.51$ & 0.355 & & \\
\hline \multicolumn{5}{|l|}{ Patient was brought by: } \\
\hline Not known & 1 & & 1 & \\
\hline Family or relatives & $1.27(0.70-2.31)$ & 0.428 & $0.68(0.38-1.23)$ & 0.205 \\
\hline Police & $2.10(1.13-3.91)$ & 0.019 & $1.63(0.86-3.08)$ & 0.135 \\
\hline \multicolumn{5}{|l|}{ Referral } \\
\hline Patient referred into the hospital & 1 & & & \\
\hline $\begin{array}{l}\text { Patient was not referred } \\
\text { Time when the patient was brought }\end{array}$ & $0.99(0.55-1.82)$ & 0.999 & & \\
\hline
\end{tabular}




\begin{tabular}{|c|c|c|c|c|}
\hline \multirow{2}{*}{ Characteristics } & \multicolumn{2}{|l|}{ Bivariate analysis } & \multicolumn{2}{|c|}{ Multivariate analysis } \\
\hline & OR $(95 \% \mathrm{CI})$ & P-Value & OR $(95 \%$ CI) & P-Value \\
\hline Day & 1 & & & \\
\hline Evening & $1.04(0.54-1.98)$ & 0.912 & & \\
\hline Night & $1.71(0.96-3.04)$ & 0.066 & & \\
\hline Interventions reference & 1 & & & \\
\hline Patient was intubated & $0.21(0.13-0.36)$ & 0.001 & $0.22(0.13-0.37)$ & 0.001 \\
\hline Antibiotics were not given & $1.67(1.00-2.77)$ & 0.049 & $2.11(1.23-3.60)$ & 0.006 \\
\hline Anti-convulsant given & $1.03(0.61-1.73)$ & 0.918 & & \\
\hline IV fluids administered & $0.73(0.42-1.29)$ & 0.28 & $0.89(0.50-1.58)$ & 0.683 \\
\hline No transfusion & $0.54(0.23-1.22)$ & 0.139 & $0.48(0.22-0.98)$ & 0.047 \\
\hline Tracheostomy tube not inserted & $2.41(1.15-5.07)$ & 0.02 & $1.82(1.01-3.62)$ & 0.049 \\
\hline \multicolumn{5}{|l|}{ Mechanism of injury } \\
\hline No mob violence & 1 & & & \\
\hline Mob violence & $0.78(0.27-2.29)$ & 0.654 & & \\
\hline Falls & $1.43(0.70-2.92)$ & 0.328 & $2.39(1.02-5.65)$ & 0.046 \\
\hline Road traffic accidents & $1.44(0.94-2.21)$ & 0.098 & $2.00(1.16-3.46)$ & 0.013 \\
\hline \multicolumn{5}{|l|}{ Number of injuries } \\
\hline Multiply-injured & 1 & & 1 & \\
\hline Not multiply-injured & $0.63(0.06-6.15)$ & 0.692 & $1.16(0.47-2.87)$ & 0.746 \\
\hline \multicolumn{5}{|l|}{ Blood pressure } \\
\hline Normotensive & 1 & & 1 & \\
\hline Hypertensive & $2.34(1.32-4.15)$ & 0.004 & $2.62(1.38-4.97)$ & 0.003 \\
\hline Hypotensive & $2.61(1.47-4.65)$ & 0.001 & $2.92(1.51-5.66)$ & 0.001 \\
\hline
\end{tabular}

\section{Discussion}

In this study, we found the burden of TBI to be very high; this is comparable to similar studies in the same setting. Tran et al. reported TBI incidence of 89/100,000 patients in Mulago hospital's neurosurgical unit [3]. This was a one-year single centre retrospective chart review that had comparatively fewer patients with STBI. In addition, they did not include ICU patients and this may account for the lower mortality. Min Li et al. reported an incidence of 7.2-811/100,000 per year depending on the location [10]. Data from New Zealand shows that rate in rural areas is higher than in urban areas, this could explain why the incidence in our setting is much higher than expected [23], considering the different mechanisms of injury in New Zealand and Uganda.

We found ICU mortality of patients with STBI at $46.9 \%$. This was higher than mortality figures from high-income countries but somewhat similar to low-income country data for example, in Kenya, Opondo et al. reported a mortality rate of 54\% in STBI patients admitted at a Kenyan ICU [12]. Similarly, in Benin, a low-income country in West Africa and Tanzania in East Africa with STBI related mortality of $47 \%[12,21]$. In the Tanzanian study, only one patient received mechanical ventilation and highlights resource constraints associated with skills, staffing and equipment. Previous studies at Mulago hospital in Uganda noted most deaths occurred during the evening and overnight shifts where the nursing coverage was significantly reduced [19]. Therefore, it is not surprising that in our study, the highest mortality occured during the nights. Objective monitoring of ICP was not done in this study, and yet ICP monitoring has been shown to improve outcomes in TBI patients managed in the ICU [31-33]. We speculate that the nature of primary brain injury could have contributed to the high mortality rate among TBI patients as shown in studies where radiological characteristics on computed tomography scans were associated with midline shift, extensive subarachnoid hemorrhage and diffuse axonal injuries, leading to higher mortality in this patient category. And most factors at bivariate and multivariate analysis were only weakly associated with death. Several studies also found that the need for mechanical ventilation in STBI patients was an independent risk factor for mortality, and all our study patients required mechanical ventilation [21,34]. This could account for the high mortality demonstrated in this particular study when compared to similar studies in similar settings since all our study patients were mechanically ventilated.

From our study, we found most TBI patients to be young male adults with a mean age of 33. This data agrees with most studies in TBI patients where similar gender and age groups of patients are admitted to ICU due to RTAs [11, 20, 21]. This is because the mechanism of injury resulting in STBI in this age bracket has not significantly changed. Males are predominantly affected because most are motorcyclist business riders which is similar to the Tanzanian situation where $49 \%$ of all RTAs involved motorcyclists [6, 20, 22]. Studies in high-income countries noted older group of patients with a mean age of 60 years and children presenting to ICU with TBI $[4,20]$. This is because the older patients being more prone to falls as opposed to RTAs; this is part of the changing epidemiology of TBI being observed in the high-income countries [4].

At multivariate logistic regression, significantly, transfusion and intubation reduced the risk of mortality by almost $50 \%$ and $80 \%$ respectively. While the mortality risk was double if a patient did not receive antibiotics or a tracheostomy. Intubation and tracheostomy both being protective against death further asserts the importance of airway management among patients with trauma [27]. Antibiotic use prophylactically prevents infections but also treats the already present infections which, by themselves, 
could cause death. Finally, patients that sustained falls and those involved in RTAs were more likely to die. This could be due to the nature and severity of the injuries these mechanisms cause which, is usually multiple and severe.

\section{Conclusion}

Our study has demonstrated a high burden of TBI to the already scarce ICU resources associated with a high mortality and prevalence of STBI among patients admitted to Ugandan ICUs. Despite limited resources in the local setting, findings from our work have shown that inexpensive and locally available measures can reduce on the length of patient's stay in the ICU and eventually decrease on the mortality. Measures such as early trauma and airway care, antibiotic use, blood transfusion plus public health safety measures may reduce on the burden of TBI as well as improve outcomes.

\section{Data Availability}

Data used to support the findings of this study can be accessed at https://osf.io/z6s7y/.

Data are available under the terms of the Creative Commons Zero "No rights reserved" data waiver (CC0 1.0 Public domain dedication). DOI 10.17605/OSF.IO/Z6S7Y.

\section{Grant Information}

The authors declared that no funding was involved in supporting this work.

\section{References}

[1] Wouter Peeters, R. v. d. B., Suzanne Polinder, Alexandra Brazinova, and H. F. L. A. I. R. M. Ewout W. Steyerberg, Epidemiology of traumatic brain injury in Europe. Acta Neurochir, 2015. 157.

[2] J. K. C Emejulu, C. M. I., C. E. Agbasoga, C. N. Ogbuagu, Traumatic brain injury in accident and emergency department of a tertiary hospital in Nigeria. East and central african journal of surgery, 2010. 15 (2).

[3] Tran, T. M., et al., Distribution and Characteristics of Severe Traumatic Brain Injury at Mulago National Referral Hospital in Uganda. World Neurosurgery, 2015. 83 (3).

[4] Bob Roozenbeek, A. I. R. M. a. D. K. M., Changing patterns in the epidemiology of traumatic brain injury. Nature reviews: Neurology, 2013. 9.

[5] WHO | Injuries and violence: the facts [Internet]. [cited 2020 Aug 1]. Available from: https://www.who.int/violence_injury_prevention/key_facts/en/.

[6] Hsia, R. Y., et al., Epidemiology of injuries presenting to the national hospital in Kampala, Uganda: implications for research and policy. international Journal of emergency medicine, 2010. 3: p. 8.

[7] Marek Majdan, D. P., Alexandra Brazinova, Martin Rusnak,
Daan Nieboer, Valery Feigin, Andrew Maas, Epidemiology of traumatic brain injuries in Europe: a cross-sectional analysis. Lancet Public Health 2016; 1: e76-83, 2016. 1.

[8] Farid Sadaka, T. M. Q., Rekha Lakshmanan and Ashok Palagiri, Management of Traumatic Brain Injury in the Intensive Care Unit, in Traumatic brain injury, F. Sadaka, Editor. 2014, intechopen. p. 592.

[9] Iftikhar Ali Raja, A. H. V., Mubasher Ahmed, Neurotrauma in Pakistan. world journal of surgery, 2001. 25: p. 8.

[10] Min Li, Z. Z., Gongjie Yu and Jianning Zhang, Epidemiology of Traumatic Brain Injury over the World: A Systematic Review. General Medicine: Open Access, 2016. 4 (5).

[11] O. E. Idowu, a. O. A., Neurotrauma burden in a tropical urban conurbation level I trauma centre. Injury, 2014. 45.

[12] E. A. Opondo and N. J. M. Mwangombe, Outcome of severe traumatic brain injury at a critical care unit: a review of 87 patients. The Annals of African Surgery, 2007. 1: p. 7.

[13] Alexis F. Turgeon MD MSc, F. L. M. M., Jean-François Simard BSc, Damon C. Scales MD PhD, et al., Mortality associated with withdrawal of life-sustaining therapy for patients with severe traumatic brain injury: a Canadian multicentre cohort study. Journal of canadian medical association, 2011. 183 (14).

[14] Helmy, A., M. Vizcaychipi, and A. K. Gupta, Traumatic brain injury: intensive care management. British Journal of anaesthesia, 2007.99 (1): p. 11.

[15] Kristin Elf; Pelle Nilsson; Per Enblad, Outcome after traumatic brain injury improved by an organized secondary insult program and standardized neurointensive care. Critical Care medicine, 2002. 30 (9).

[16] Patel, H. C., et al., Specialist neurocritical care and outcome from head injury. Intensive Care Medicine 2002. 28.

[17] Kesinger, M. R., et al., A standardized trauma care protocol decreased in-hospital mortality of patients with severe traumatic brain injury at a teaching hospital in a middleincome country. Injury, 2014. 45 (9): p. 1350-1354.

[18] Atumanya P, Sendagire C, Wabule A, Mukisa J, Ssemogerere L, Kwizera A, et al. Assessment of the current capacity of intensive care units in Uganda; A descriptive study. J Crit Care. 2020 Feb; 55: 95-9.

[19] R. J. Kruisselbrink, L. S., A. Kwizera, J. V. B Tindimwebwa, Mortality Rate And Associated Factors Among Intensive Care Unit Patients At Mulago Hospital, Uganda: A Prospective Cohort Study. American journal of respiratory and critical care medicine, 2014. 189

[20] Abdelgadir, J., et al., Epidemiology and Characteristics of Neurosurgical Conditions at Mbarara Regional Referral Hospital. World Neurosurgery.

[21] KU Tobi, A. A., SO Agbedia, Outcome of traumatic brain injury in the intensive care unit: a five-year review. Southern African Journal of Anaesthesia and Analgesia, 2016. 22 (5).

[22] Staton, C. A., et al., A prospective registry evaluating the epidemiology and clinical care of traumatic brain injury patients presenting to a regional referral hospital in Moshi, Tanzania: challenges and the way forward. Int J Inj Contr Saf Promot, 2015. 24 (1): p. 69-77. 
[23] Feigin, V. L., et al., Incidence of traumatic brain injury in New Zealand: a population-based study. The Lancet Neurology, 2012. 12 (1): p. 53-64.

[24] Girling, K., Management of head injury in the intensive-care unit. Continuing Education in Anaesthesia, Critical Care \& Pain 2004. 4 (2).

[25] Scott. A. Marshall, G. S. F. L., Critical care managenent of traumatic brain injury, in Comprehensive critical care: Adult, R. R. T. Pamela R Roberts, Editor. 2012, Society of critical care medicine: united states of America.

[26] Griesdale, D. E., et al., Glucose control and mortality in patients with severe traumatic brain injury. Neurocrit Care, 2009. 11 (3): p. 311-6.

[27] Arabi, S. H. H. a. Y. M., Critical care management of severe traumatic brain injury in adults. Scandinavian Journal of Trauma, Resuscitation and Emergency Medicine, 2012. 20 (12): p. 15 .

[28] Rostami, E., Glucose and the Injured Brain-Monitored in the Neurointensive Care Unit. Frontiers in Neurology, 2014. 5 (91).

[29] Legrand, M. and D. Payen, Understanding urine output in critically ill patients. Annals of Intensive Care, 2011. 1: p. 1313.

[30] Mehmood A, Zia N, Hoe C, Kobusingye O, Ssenyojo H,
Hyder AA. Traumatic brain injury in Uganda: exploring the use of a hospital based registry for measuring burden and outcomes. BMC Res Notes [Internet]. 2018 May 15 [cited 2020 Jul 17]; 11. Available from: https://www.ncbi.nlm.nih.gov/pmc/articles/PMC5952367/.

[31] Agrawal D, Raghavendran K, Schaubel DE, Mishra MC, Rajajee V. A Propensity Score Analysis of the Impact of Invasive Intracranial Pressure Monitoring on Outcomes after Severe Traumatic Brain Injury. J Neurotrauma. 2016 01; 33 (9): 853-8.

[32] Rahmanian A, Haghnegahdar A, Rahmanian A, Ghaffarpasand F. Effects of Intracranial Pressure Monitoring on Outcome of Patients with Severe Traumatic Brain Injury; Results of a Historical Cohort Study. Bull Emerg Trauma [Internet]. 2014 Oct [cited 2020 Jul 17]; 2 (4): 151-5. Available from: https://www.ncbi.nlm.nih.gov/pmc/articles/PMC4771290/.

[33] Farahvar A, Gerber LM, Chiu Y-L, Carney N, Härtl R, Ghajar J. Increased mortality in patients with severe traumatic brain injury treated without intracranial pressure monitoring. J Neurosurg. 2012 Oct; 117 (4): 729-34.

[34] Holland MC, Mackersie RC, Morabito D, Campbell AR, Kivett VA, Patel R, et al. The development of acute lung injury is associated with worse neurologic outcome in patients with severe traumatic brain injury. J Trauma. $2003 \mathrm{Jul} ; 55$ (1): 106-11. 